\title{
MINI-REVIEW
}

\section{STRATEGIES OF SUBCELLULAR FRACTIONATION SUITABLE FOR ANALYSIS OF PEROXISOMES AND MICROPEROXISOMES OF ANIMAL TISSUES}

\author{
M. J. CONNOCK ${ }^{1}$ and N. J. TEMPLE ${ }^{2}$ \\ ${ }^{1}$ Department of Biological Sciences, The Polytechnic, Wolverhampton, WVI ILY. U.K. \\ ${ }^{2}$ Department of Biochemistry, Escuela de Medicina de Cayey, Box 935, Cayey 00634, Puerto Rico
}

(Received 11 May 1982)

\begin{abstract}
Strategies of subcellular fractionation are reviewed from the perspective of their utility in the analysis of peroxisomes. The considerable potential inherant in the method of rate dependent banding in zonal rotors is emphasized. The use of various density gradient solutes is considered.
\end{abstract}

\section{INTRODUCTION}

De Duve (1969a,b) has defined peroxisomes as organelles containing catalase together with one or more $\mathrm{H}_{2} \mathrm{O}_{2}$ producing oxidases. The peroxisomes of liver have been much studied by biochemical, histochemical and whole organ spectrophotometric methods. Rclatively little attention has been devoted to other tissues. However, Novikoff \& Novikoff (1972) introduced the term "microperoxisome" to describe "elongate or roughly spherical cytoplasmic organelles, ranging in size from approx. $0.1 \mu-1.0 \mu$, containing a moderately electron-opaque matrix, lacking a nuclooid and delimited by a tripartite membrane which is continuous via numerous slender connections... with the tripartite smooth ER (endoplasmic reticulum) membrane .... and generally giving a positive "histochemical" rcaction for catalase" (Novikoff et al., 1973). Histochemistry demonstrating catalase at the electron microscope level revealed that particles fitting this definition are ubiquitous in mammalian cells (Hruban et al., 1972; Novikoff et al., 1973)*. This data built upon the earlier observations of Hruban \& Rechcigl (1969)

In recent years there has been a quickening of interest in animal peroxisomes because concrete evidence has been supplied of their involvement in lipid metabolism. Thus liver peroxisomes have been shown to oxidise fatty acid (Lazarow \& De Duve, 1976) and to be the site of dihydroxyacetone phosphate acyltransferase activity (Hajra et al., 1979), and toad bladder microperoxisomes were shown to contain the glyoxylate cycle enzyme malate synthase (Goodman et al., 1980). In view of these recent findings two questions arise: do tissues other than liver have lipid metab-

\footnotetext{
* For the purpose of this review we have assumed that the catalase staining particles observed by electron microscopy in many animal tissues, and which are often termed microperoxisomes, are identical with the particulate catalase activity demonstrated by centrifugation and biochemical assay of catalase.
}

olising enzymes in their catalase particles (or microperoxisomes) and can these particles universally be described as peroxisomes in stricto sensu? The answer to these questions depends largely on suitable subcellular fractionation studies being performed.

Several reviews have appeared pertaining to various aspects of the biology of peroxisomes (Baudhuin, 1969; De Duve \& Baudhuin, 1966; Tolbert \& Essner, 1981; Tolbert, 1981; Masters \& Holmes, 1977; Hogg, 1969; Richardson, 1974; De Duve, 1969a; Vigil, 1973; Seis, 1974; Muller, 1975; Reide et al, 1980) and some (e.g. Bock et al., 1980; Baudhuin, 1974) have devoted attention to the methods available for subcellular fractionation and subsequent analysis of these organelles. However, most of these latter articles have been almost exclusively concerned either with plant or with mammalian hepatic and renal peroxisomes. The purpose of the present brief review is to highlight fractionation strategies suitable for the analysis of peroxisomes and microperoxisomes of various animal tissues. Only centrifugation methods will be considered and the terms defined by Reid \& Williamson (1974) will be used. We will not reiterate the general principles of analytical subcellular fractionation detailed by De Duve, Beaufay \& coworkers (e.g. De Duve, 1971; De Duve \& Beaufay, 1981; Beaufay \& Amar-Costesec, 1976) other than to point out here the importance of calculating balance sheets and of bearing in mind the assumptions embodied in the postulates of "unique localisation" and of "biochemical homogeneity" when using markers for subcellular organelles.

\section{DESIRABLE PROPERTIES OF FRACTIONATION STRATEGIES}

The study of liver peroxisomes has emphasised that numerous peroxisomal enzymes are not exclusive to these organelles but may be shared with mitochondria, microsomes or cytosol. For apparently cytosolic activities it is generally uncertain whether the activity has been released from damaged organelles or 
whether it is a bona fide representative of the cell sap. De Duve (1967) has emphasised that because both peroxisomes and mitochondria are respiratory $\mathrm{CO}_{2}$ consuming) organelles it must be expected (and in fact has been demonstrated) that they will share several enzyme activities. In vicw of these considerations it is clear that the primary requisite of a fractionation strategy designed to allow the analysis of peroxisomes is that these organelles be well separated especially from mitochondria but also from microsomes and cytosol (the cytosol, of course, presents few problems). Further desirable properties are minimal damage to organelles so as to prevent enzyme leakage, yield of organelles sufficient for biochemical study, cheapness of gradient materials and ease and speed of operation.

\section{A. SUCROSE MEDIA}

\section{Differential pelleting}

Of available techniques the now classical differential pelleting scheme (De Duve et al., 1955) which separates homogenate into 5 subcellular fractions $(N$, $\mathrm{M}, \mathrm{L}, \mathrm{P}$ and $\mathrm{S}$ ) represents the simplest in terms of equipment required. It is capable of large yiclds. Its major disadvantages are the need for repeated pelleting and resuspension of organelles which is likely to be injurious and to cause aggregation, that it is relatively time consuming, and that when unsupplemented by subsequent procedures gives a generally
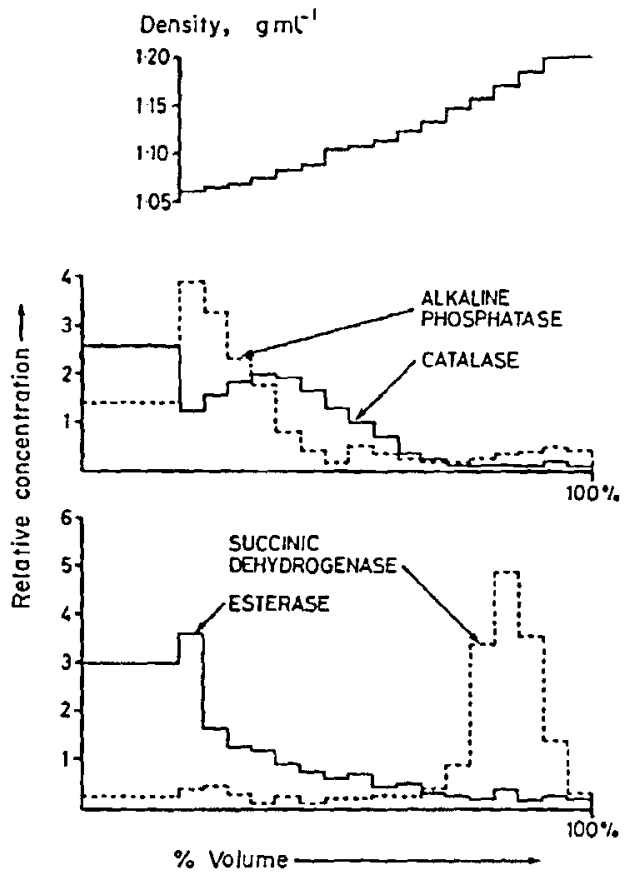

Fig. 1. Rat small intestine post-nuclear supernatant analysed by rate dependent banding. Centrifugation in a B.XIV zonal rotor for $45 \mathrm{~min}$ at $16,000 \mathrm{rev} / \mathrm{min}$ at $6^{\mathrm{C}} \mathrm{C}$. The markers for subcelfular organelles were: Alkaline phosphatase for brush borders, succinic dehydrogenase for mitochondria, esterase for microsomes, and catalase for microperoxisomes. The sucrose gradient (15 to $32 \% \mathrm{w} / \mathrm{w}$ ) rested on a cushion of $56 \% \mathrm{w} / \mathrm{w}$ sucrose. [Results presented as described by Bcaufay \& Amar Costesec, 1976]
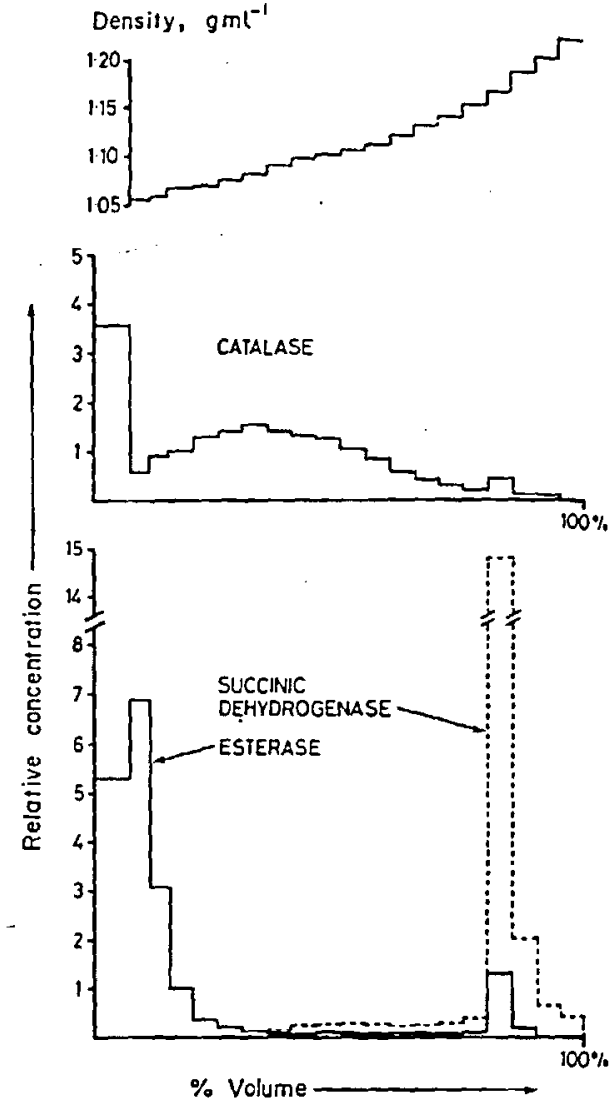

Fig. 2. Mouse BAT post-nuclear supernatant analysed by rate dependent banding in a B-XIV zonal rotor. Details as in Fig. 1.

poorer resolution than other methods. The scheme was first developed for rat liver and De Duve has cautioned against indiscriminate adoption for other tissues. Most mammalian tissues contain microperoxisomes of considerably smaller size than the peroxisomes of liver or of rat renal tubules and consequently in differential pelleting these require greater integrals of time and centrifugal force to sediment them. Consequently, to separate microperoxisomes from microsomes by this method resuspension and recentrifugation would need to be repeated several times. Resuspension of such hard pelleted microperoxisomes is likely to be traumatic and is best avoided Tolbert (1974) has even advocated the avoidance of pelleting in analysis of liver peroxisomes.

\section{Rate dependent banding}

(Reid \& Williamson, 1974). This is an alternative procedure which, like differential pelleting, exploits the differences in sedimentation rate between peroxisomes on the one hand and mitochondria and micro somes on the other. It can be done with tubes or with zonal rotors but the latter are far superior and more convenient. Preferably a long path length zonal rotor (e.g. B-XIV) is used. It has been found using this procedure that intestinal microperoxisomes of various species including guinea-pig (Connock et al., 1974) mouse, (Small at al., 1981) goldfish (Connock, 1973i 


$$
\text { Density, } g m t^{-1}
$$
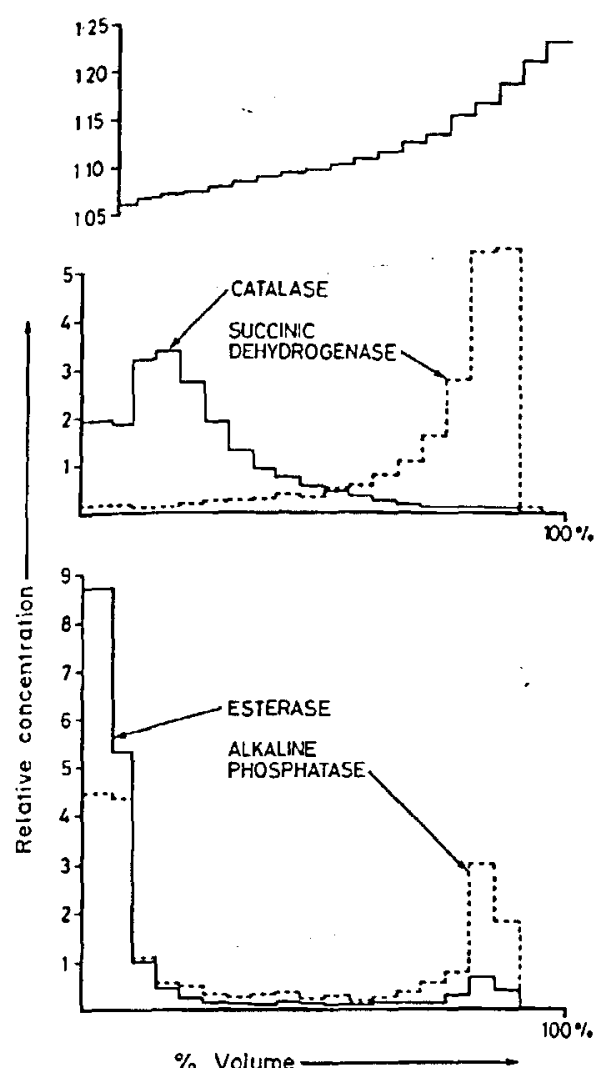

Fig. 3. Mouse kidney post-nuclear supernatant analysed ty rate dependent banding in a B-XIV zonal rotor. Details as in Fig. 1 , except that centrifugation was for $8 \mathrm{~min}$ at $16,000 \mathrm{rev} / \mathrm{min}$. and rat (Peters \& Shio, 1976) (Fig. 1) can be reasonably well separated from microsomes (which sediment more slowly) and especially well separated from mitochondria (which sediment more quickly). Similar separations can be achieved for lung (Goldenberg et al., 1978) and for brown adipose tissue (BAT) microperoxisomes (Fig. 2).

Most mammalian tissucs contain microperoxisomes of similar size to those of lung. BAT and intestine and these, in theory, should be nicely separated by this method. Fibroblasts also contain microperoxisomes which have a slower sedimentation rate than mitochondria (Tulkens et al., 1974) and this has been exploited in an alternative procedure using the Beaufay (short path length) zonal rotor (Sun \& Poole, 1975). Baggiolini et al. (1978) have designed an adaptor for the B-XIV zonal rotor that halves its capacity while retaining full path length characteristics. This adaptation makes the rotor more suitable for rate dependent banding with preparations capable of only small yield of starting homogenate (e.g. cell culture samples)..

Rate dependent banding in a zonal rotor also gives a good separation of peroxisomes from mitochondrial markers when mouse liver or kidney are analysed (Figs 3 and 4). Because of the larger size of these peroxisomes smaller integrals of centrifugal force and time are required compared with tissues containing smaller microperoxisomes. In practice the best rate dependent banding separations are achieved if the sample layer is introduced slowly by perfusion pump at no more than $5 \mathrm{ml} / \mathrm{min}$ so as to create a discrete sample band (Cline, 1971). Also a long shallow gradient should be used (e.g. 15 to $30 \% \mathrm{w} / \mathrm{w}$ sucrose) so that particles are not slowed by approaching their equilibrium density; particles will only be arrested if they have traversed the whole gradient and reached the dense cushion. The advantages of rate dependent
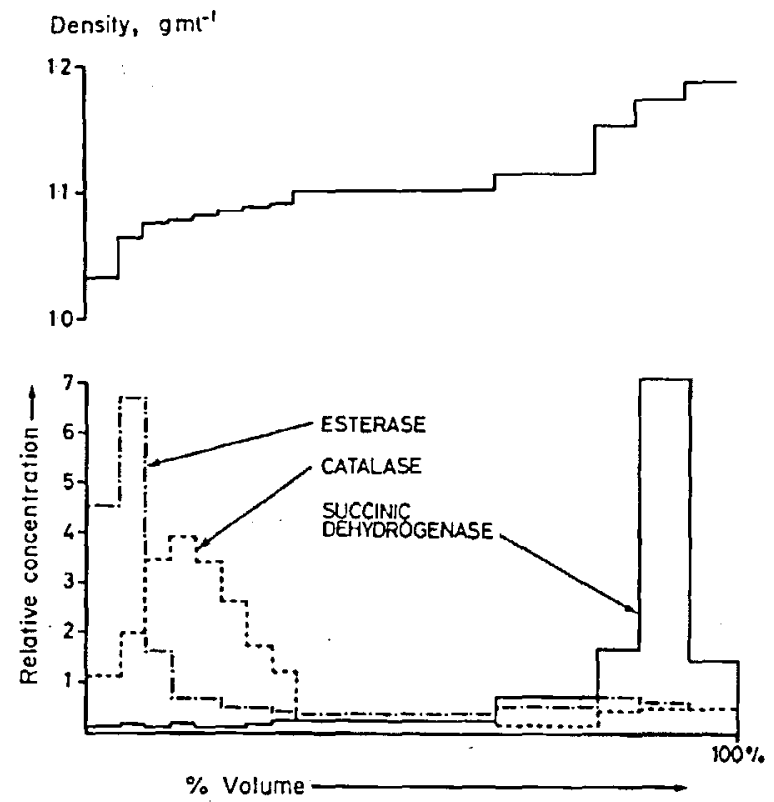

Fig. 4. Mouse liver post-nuclear supernatant analysed by rate dependent banding in a B-XIV zonal rotor. Details as Fig. 3. 

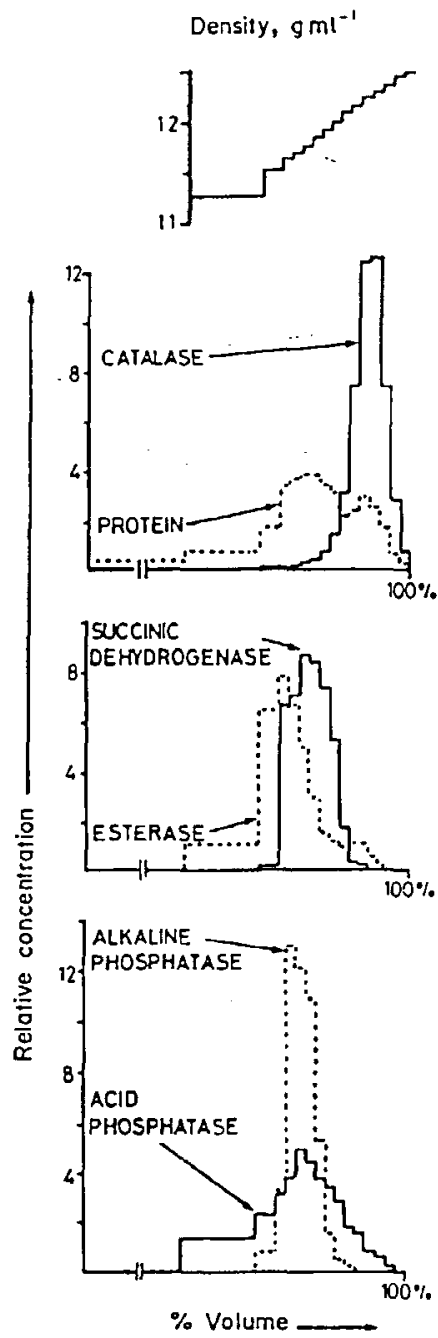

Fig. 5. Mouse kidney. Density dependent banding of peroxisome-enriched fractions from a rate dependent banding experiment like that shown in Fig. 3 except that pyrophosphate was used $(2 \mathrm{ml}$ of $100 \mathrm{mM}$ pyrophosphate.pH 8.2 was mixed with $28 \mathrm{ml}$ of post-nuclear supernatant just before loading the zonal rotor for the rate separation). A small volume $(40 \mathrm{ml})$ sucrose gradient $(30$ to $52 \% \mathrm{w} / \mathrm{w})$ was used with a $56 \% \mathrm{w} / \mathrm{w}$ sucrose cushion. Centrifugation was at $25,000 \mathrm{rev} / \mathrm{min}$ for $4.5 \mathrm{hr}$ with a $200 \mathrm{ml} 15 \% \mathrm{w} / \mathrm{w}$ sucrose overlay and a $150 \mathrm{ml}$ sample band. Details as in Fig. 3 except that acid phosphatase has been used as a marker for lysosomes.

banding in a zonal rotor are the especially good resolution of microperoxisomes from mitochondria and the reasonably good separation from microsomes, speed and convenience of operation, lack of damage to organelles and the fact that it can easily be coupled with subsequent concentration of the dispersed peroxisomes or microperoxisomes by pelleting or by density dependent banding in a small volume gradient (this can be done without dilution and osmotic shock because they will not have approached their equilibrium density). The major disadvantage of the method is its relatively low yield because for good separations a narrow sample band must be used (e.g. $\sim 30$ to
$40 \mathrm{ml}$ in a B-XIV rotor) and this must not be too concentrated (e.g. 10-20\% w/v tissue homogenate) or else unwanted droplet sedimentation may occur. Dobrota \& Hinton (1980) and Anderson et al. (1980) have preceded rate dependent banding in a zonal rotor by differential pelleting of rat hepatic or renal large particles. This has allowed the use of a greater concentration of organelles in the sample layer and thereby increases the yield of rate dependent banding separations without sacrifice of resolution. Consider. able care is required in resuspending the pellets used for such sample bands. Damage to organelles must be minimised while achieving maximal disaggregation of the particles. Liver peroxisomes are more suitable for this procedure than are most microperoxisomes since the latter would have to be resuspended from hard impacted pellets. Usually sufficient yield is achieved in a rate dependent banding run if crude homogenate or post-nuclear supernatant is loaded into the rotor. If, after the banding, particle concentration is too low then organelles can easily be concentrated by pellet. ing or by density dependent banding in a small volume gradient (e.g. Fig. 5).

\section{Density dependent banding}

Density dependent banding in sucrose gradients has been the principle procedure for obtaining useful peroxisome-enriched fractions. The now classical method reported by Leighton et al. (1968) yielded per. oxisomes estimated to be $95 \%$ pure from the livers of rats treated with Triton WR-1339 so as to allow separation from lysosomes. The density banding step was preceded by differential pelleting to produce the " $i$ " fraction greatly depleted in microsomes and enriched $\sim 2$ times for peroxisomes with respect to mitochondria. If a tube held gradient [instead of one held in a zonal rotor (Beaufay type)] is used for the final step then purity is reduced [purification factor for catalase of 27 compared with 36 (Baudhuin, 1974)]. A similar procedure, but without Triton WR-1339 treatment has been used by Goldenberg et al. (1978) to purifi; fish (carp) liver peroxisomes $\sim 40$ times. Triton WR-1339 should be used only with the realisation that the levels of peroxisomal enzyme activities are likely to be decreased (Ishi et al., 1979).

Tolbert (1974) has advocated the use of a single density dependent banding of homogenate or postnuclear supernatant in a zonal rotor for the analysis of hepatic and renal peroxisomes. Obviously, the purity of peroxisomc fractions so obtained will be less than that if the density step is preceded either by differential pelleting (Leighton et al., 1968) or by rate dependent banding in a zonal rotor. Because of the generally appreciable difference in equilibrium density between peroxisomes and mitochondria from liver and kidney this single banding procedure is reasorably efficient with these tissues and allows the detection of peroxisomal enzyme locations if the proportion of activity in the peroxisomes is of the order of $15-20 \%$ or greater. Lower proportions in peroxisomes would probably require greater purification of peroxisomal fractions for unequivocal demonstration of location. On the other hand microperoxisomes of tissues analysed so far (e.g. Peters \& Shio, 1976; Connock et al. 1974) do not differ so much from mitochondria in their equilibrium density, therefore, ${ }^{3}$ 
ingle density dependent banding step is less satisfacsingle for analysis of microperoxisomes and is best tory for with a preliminary rate dependent banding or differential pelleting step. The relative merits of these iwo preliminary procedures, in our opinion, weigh in iNo preliminate dependent banding in a zonal rotor farour where very high yields are required. The major except whes being lack of damage (especially in the adran of microperoxisomes) and superior separation from mitochondria. However, contamination of perfrom misomes with microsomes may be somewhat greater than when differential pelleting is used. It is therefore diantageous in the subsequent density dependent step to reduce the "time $x$ centrifugal force" integral step nuch as possible so that the slower sedimenting microsomes do not reach equilibrium and thereby cause less contamination of peroxisomal fractions. An alternative and/or additional strategy is to pretreat the pay load (or homogenate) with EDTA or pyrophosphate (see Fig. 5) which Amar-Costesec et al. (1974) have shown to reduce the equilibrium density of endoplasmic reticulum elements by stripping them of ribosomes and protein. This procedure was cxploited by Dobrota \& Hinton (1980) to aid the large scale purification of hepatic lysosomes from untreated rats (peroxisomes were removed by appropriate rate dependent procedures prior to the final density dependent banding).
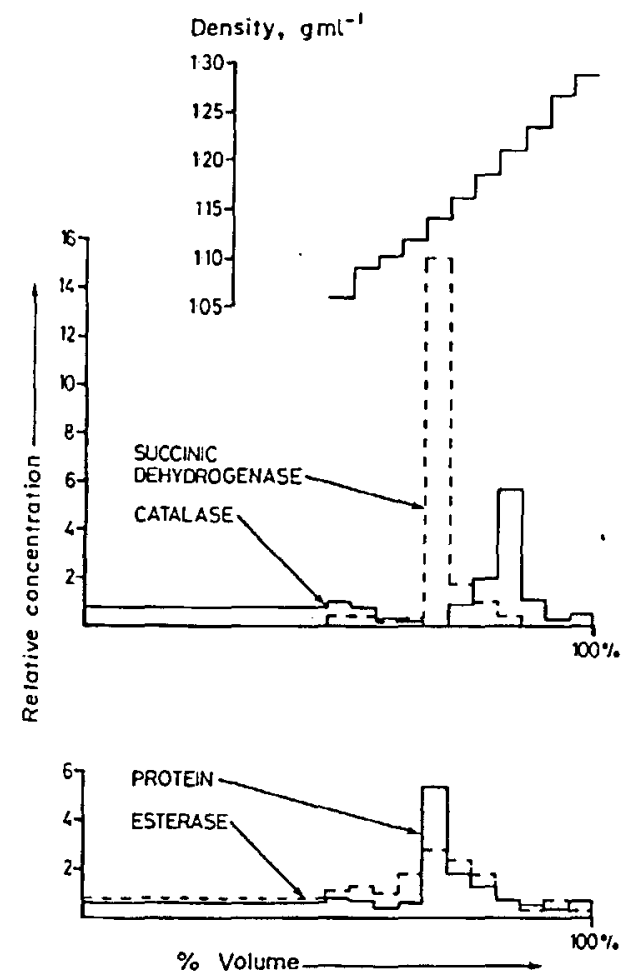

Fig. 6. Hamster BAT post-nuclear supernatant analysed by density dependent banding in a metrizamide gradient. Centrifugation was at $25,000 \mathrm{rev} / \mathrm{min}$ using a $25 \mathrm{ml} 3$-place sxing-bucket rotor $\left(g_{\max }=90,000\right)$. Other details as in Fig. 1.

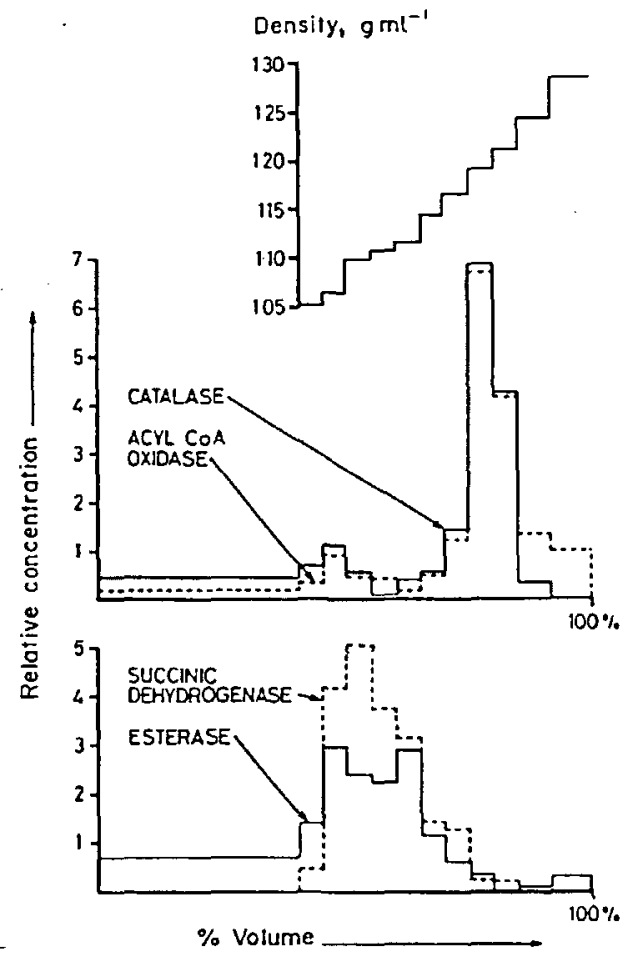

Fig. 7. Goldfish intestine post-nuclear supernatant analysed on a metrizamide gradient. Details as in Fig. 6.

\section{B. OTHER MEDIA}

Two other media have been introduced recently which allow separation of peroxisomes of reasonable purity. Walliaux et al. (1978) found that a linear metrizamide density gradient gave as good a separation of peroxisomes from other liver organelles as did the sucrose gradient method of Leighton et al. (1968). An advantage of this procedure is that it obviates the use of Triton WR-1339 to ensure a good separation from lysosomes. Metrizamide gradients have been used successfully in the investigation of human liver peroxisomes (Bronfman et al., 1979). We observed reasonable separation of mouse renal peroxisomes using density dependent banding on a metrizamide gradient (Small et al., 1981). Does metrizamide hold the same promise from micropcroxisomes as it does for renal and hepatic peroxisomes? Figure 6 and 7 show that this is the case for microperoxisomes of hamster BAT and goldfish intestine, and we have observed similar results with insect fat body (Connock et $a l ., 1982$ ) and guinea pig small intestinal microperoxisomes (Small et al., 1980). In all instances the use of a metrizamide gradient results in a good separation of peroxisomes from lysosomes thus eliminating the use of Triton WR-1339 or other lysosome perturbing agents. So far metrizamide gradients have only been used with post-nuclear supernatant or crude homogenate or in combination with preliminary differential pelleting. In theory we would expect the best purifications to be achieved by combining pyrophosphate treatment and rate dependent banding through a sucrose gradient in a zonal rotor with subsequent den- 
sity dependent banding in a metrizamide gradient. The latter step, because of the large volume of the sample to be loaded, would also be best performed in a zonal rotor. However, the relative expense of metrizamide might rule out this strategy. Information so far available indicates that for peroxisomes and microperoxisomes metrizamide gradients are equal or su. perior to those of sucrose with density dependent banding procedures. Unfortunately, the expense of metrizamide means that its resolving power might not be fully exploited by using zonal rotors.

Neat et al. (1981) and Appelkvist et al. (1981) recently reported procedures for isolating purified rat liver peroxisomes in self generated Percol gradients held (in the former method) in a vertical tube rotor. The advantages of the method are its speed, the fact that Percol gradients can be made isosmotic, and the facility of analysing several samples simultaneously in the multi-place rotor. The main disadvantages appear to be the moderate purification achieved and the fact that percol must be removed prior to some biochemical analyses being performed. Percol gradients as yet seem not to have been used for isolating microperoxisomes.

\section{CONCLUSION}

In this brief review we have aimed to highlight fractionation strategies likely to be useful for analysis of peroxisomes and microperoxisomes from a variety of animal tissues. The considerable resolution between mitochondria and peroxisomes that is achieved by rate dependent banding in a zonal rotor appears to us to hold considerable promise and to have been underexploited. Hinton \& Dobrota (1980) have similarly advocated what they call the "s-p" approach for analysis of the heterogeneity of organelles. It would appear to us that by coupling available fractionation strategies with oxidase assays that exploit sensitive methods for detection of $\mathrm{H}_{2} \mathrm{O}_{2}$ (e.g. Guilbault et al., 1968; Kochli \& Von Wartburg, 1978) and with histochemistry using diaminobenzidene (Hand, 1979) and cerous ion methods (Briggs et al., 1975) it should be possible to answer some of the outstanding questions concerning the nature of the microperoxisomes that are ubiquitous in mammalian cells.

Acknowledgements-We thank the Wellcome Trust and Science Research Council (U.K.) for financial support. We thank Gill Small and Anne Silcox for use of their unpublished results.

\section{REFERENCES}

Amar-Costesec A. IVibo M. Thises-Sempoux D. BeauFAY H. \& BERTIET J. (1974) Analytical study of microsomes and isolated subcellular membranes from rat liver IV J. cell. Biol. 62, 717-745.

ANderson K., HaGa H. J. \& Dobrota M. (1980) Heterogeneity of rat kidney-cortex lysosomes fractionated by gradient centrifugation in zonal rotors. Biochem. Soc. Trans. 8, 597-598.

Appelkivist E. L., Brunk U. \& Dallner G. (1981) Isola. tion of peroxisomes from rat liver using sucrose and percol gradients. J. biochem. Biophys. Meth. 5, 203-217.

Baggiolini M., Dewald B. \& Bretz U. (1978) A volume adapter for use in a B-XIV zonal rotor. Analyt. Biochem. $91,123-129$
Baudhuin P. (1969) Peroxisomes. In Handbook of Molecu. lar Cytology (Edited by Lima-De-FAkia A.) Pp. 1179-1195. Elsevier Holland, Amsterdam.

BaudluUin P. (1974) Isolation of rat liver peroxisomes In Methods in Enzymology (Edited by FieISCHER S. \& Packer L.) Vol. XXXI, pp. 356-368. Academic Press New York.

Beaufay H. \& Amar-Costesec A. (1976) Cell fractionation techniques. In Methods in Membrane Biolog) (Edited b. KorN E. D.) pp. 1-100. Plenum, New York.

Bock P., Kramar R. \& Pavelka M. (1980) Peroxisomer and Related Particles in Animal Tissues pp. 239. Springer Verlag, IVien, New York.

Briggs R. T., Drath D. B., Karnovsky M. L. \& K KarsovsKY M. J. (1975) Localization of NADH oxidase on the surface of polymorphonuclear leukocytes by a new cytochemical method. J. cell. Biol. 67, 566-586.

Brostrman M., Inestrosa N. C. \& Leighton F. (1979, Fatty acid oxidation by human liver peroxisomes. $B_{i a}$ chem. biophys. Res. Commun. 88, 1030-1036.

CliNe G. B. (1971) In Separations with Zonal Rolor (Edited by ReID E.) pp. Z-2.6. University of Surte: Guildford.

Cowsock M. J. (1973) Intestinal peroxisomes in the gold. fish (Carassius auratus). Comp. Biochem. Physiol. 45. 945-951.

CoNNock M. J., Kirk P. R. \& Sturdee A. P. (1974) A zonal rotor method for the preparation of microperoxsomes from epithelial cells of guinea-pig small intestine J. cell. Biol. 61, 123-133.

Coniock M. J., Ward D. R. \& Shaw N. (1982) Evidero for peroxisomal fatty acid oxidation in beetle fat body: Detection and subcellular localization of acyl-COA oxidase in fat body of the cockchafer (Melolontha melolon tha). Comp. Biochem. Physiol. In press.

De Duve C. (1967) Criteria of homogeneity and purity of mitochondria. In Methods in Enzymology (Edited b Estabroox R. W. \& Pullian M. E.) Vol. X, pp. 7-18 Academic Press, New York.

DE DUV'E C. (1969, a) The peroxisome: a new cytoplasmi organelle. Proc. R. Soc. B. 173, 71-83.

DE DUVE C. $(1969, \mathrm{~b})$ Evolution of the peroxisome. Anr. N.Y. Acad. Sci. 168, 369-381.

DE DUVE C. (1971) Tissue fractionation past and present. J. cell Biol. 50, 20D-55D.

De Duve C., Pressman B. C., Gianetto R., Wattiaux R. \& Appelsians F. (1955) Tissue fractionation studies. 6 Intracellular distribution patterns of enzymes in rat-liver tissue. Biochem. J. 60, 604-617.

De Duve C. \& Baudiuin P. (1966) Peroxisomes (microbodies and related particles). Physiol. Ret. 26, 323-357.

De Duve C. \& Beaufay H. (1981) A short history of tissux fractionation. J. cell. Biol. 91, 293S-299S.

Dobrota M. \& HiNton R. H. (1980) Large scale prep aration of highly purified lysosomes from normal rat liver. Analyz. Biochem. 102, 97-102.

Goldexterg H. Huttivger M. KaUpfer P. \& Krali R. (1978) Preparation of peroxisomes from carp liver $b$ ! zonal rotor density gradient centrifugation. Histochem. $j$. $10,103-113$.

Goldexberg H., Kollner U., Kramar R. \& Patelka M (1978) Catalase-positive particles from pig lung. Bir chemical preparation and morphological studies. Histo chemistry 56, 253-264.

Goodman D. B. P., Davis W. L. \& JoNes R. G. (1950 Glyoxylate cycle in toad urinary bladder: possible stiml. lation by aldosterone. Proc. natn. Acad. Sci., U.S.A. 7t. 1521-1525.

Guilbault G. G., Brignac P. \& Zimmer M. (1968) Homo vanillic acid as a fuorimetric substrate for oxidatis: enzymes. Analytical applications of the peroxidase, qut cose oxidase and xanthine oxidase systems. Analy Chem. 40, 190-196. 
U. K., Burke C. L. \& JoNes C. L. (1979) Subcellular localisation of acyl coenzyme $A$ : dihydroxyacetone phosthate acyltransferase in rat liver peroxisomes (Microbodics). J. biol. Chem. 254, 10896-10900.

HA:D A. R. (1979) Cytochemical detection of peroxisomal Hasidases. J. Histochem. Cytochem. 27, 1367-1370.

oxiso: R. H. \& Dobrota M. (1980) Use of s-p methods in the study of heterogeneity in organelles. Biochem. Soc. Trans. 8, 515-516.

HOGG J. F. (1969) (Ed) The nature and function of peroxisomes (Microbodies, Glyoxysomes). Ann. N.Y. Acad. Sci. $168,209-381$.

IIRLDAN Z. \& Recilcigl M. (1969) Microbodies and related particles. Morphology, biochemistry and physiology. Int. Ret. Cytol. 20 Suppl 1. pp. 296.

HRL'BAN Z., VIGIL E. L. \& Slesers A. (1972) Microbodies. Constituent organelles of animal cells. Lab. Imest. 27, 184-191.

Ish HI. SLGa T., Hayashi H. \& NuNobe S. (1979) Effect of Triton IVR-1339 on peroxisomal enzymes of rat liver. Biochim. biophys. Acta 582, 213-220.

KoChLI H. \& VoN Wartburg J. P. (1978) A sensitive photometric assay for monoamine oxidase. Analyt. Biochem. 84, 127-135.

Lazarow P. B. \& De Duye C. (1976) A falty acyl-CoA oxidizing system in rat liver peroxisomes; enhancement by clofibrate, a hypolipidemic drug. Proc. natn. Acad. Sci., U.S.A. 73, 2043-2046.

leghion F., Poole B., Beaufay H., Baudhuin P., Coffey J. W., Fow'Ler S. \& DE DUYe C. (1968) The large-scale separation of peroxisomes, mitochondria and lysosomes from the livers of rats injected with Triton WR-1339. $J$. cell. Biol. 37, 482-513.

Masters C. \& Hol.Mes T. (1977) Peroxisomes: New aspects of cell physiology and biochemistry. Physiol. Ret. 57, 816-882.

MLLLER M. (1975) Biochemistry of protozoan microbodies: peroxisomes, I-glycerophosphate oxidase bodies, hydrogenosomes. A. Rer. Microbiol. 29, 467-483.

Neat C. E. Thomassen M. S. \& OsmundseN H. (1981) Effects of high-fat diets on hepatic fatty acid oxidation in rat. Biochem. J. 196, 149-159.

Nonikoff A. B., Novikoff P. M., Davis C. \& Quintana N. (1973) Studics on microperoxisomes V. Are microperoxisomes ubiquitous in mammalian cells? J. Histochem. Cytochem. 21, 737-755.

Novikoff P. M. \& Novikoff A. B. (1972) Peroxisomes in absorptive cells of mammalian small intestine. $J$. cell. Biol. 53, 532-560.

Novikoff P. M., Novikoff A. B., Quintana N. \& Davis
C. (1973) Studies on microperoxisomes. III. Observations on human and rat hepatocytes. J. Histochem. Cytochem. 21, 540-558.

Peters T. J. \& Smo H. (1976) Analytical subcellular fractionation studies on rat liver and on isolated jejunal enterocytes with special reference to the separation of lysosomes, peroxisomes and mitochondria. Clin. Sci. molec. Med. 50, 355-366.

RFid E. \& Wiltiasison R. (1974) Centrifugation. In Methods - in Enzjmology (Edited by Flesscuer S. \& Packer L.) Vol. XXXI, pp. 713-733. Academic Press, New York.

Richakdoson M. (1974) Microbodies (glyoxy'somes and peroxișomes) in plants. Sci. Prog., Oxford 61, 41-61.

RIEDE U. N., MoORE W. \& SANDrItTer W. A. (1980) Structure and function of peroxisomes and their role in disease processes. In Pathobiology of Cell Mombrames (Edited by Trump B. F. \& Arstila A. U. Vol. II, pp 174-220. Academic Press, New York.

SEIS H. (1974) Biochemistry of the peroxisome in the liver cell. Angew: chem. Int. Ed. Engl 13, 706-718.

Sirall G. M., Brolly D. \& CoNiNock M. J. (1980) Palmitoy!-CoA oxidase: detection in several guinea-pig tissues and peroxisomal localisation in mucosa of small intestine. Life Sci. 27, 1743-1751.

Sirali. G. M., Hockisg T. J., Sturdee A. P., Burdett K. \& CoNiock M. J. (1981) Enhancement by dietary clofibrate of peroxisomal palmityl-CoA oxidase in kidney and small intestine of albino mice and liver of genetically lean and obese mice. Life Sci. 28, 1875-1882.

Sun A. S. \& POOLE B. (1975) Fractionation of rat fibroblasts in a zonal rotor by means of a viscosity barrier. Analyt. Biochem. 68, 260-273.

TOLBERT N. E. (1974) Isolation of subcellular organelles of metabolism on isopycnic sucrose gradients. In Methods in Enzymology XXXI (Edited by Fleischier S. \& PACKer L.) pp. 734-746. Academic Press, New York.

TOLneRT N. E. (1981) Metabolic pathways in peroxisomes and glyoxysomes. A. Rev. Biochem. 50, 133-157.

TOlbert N. E. \& EssNer E. (1981) Microbodies: Peroxisomes and glyoxysomes. J. cell. Biol. 91, 271S-283S.

TulkeNs P., Beaufay H. \& Trouet A. (1974) Analytical fractionation of homogenates from cultured rat embryo fibroblasts. J. cell. Biol. 63, 383-401.

VIGIL E. L. (1973) Structure and function of plant microbo. dies. Sub-cell. Biochem. 2, 237-285.

Wattiaux R., Wattiaux-De CoNinck S., RonveauxDupal M. \& DuroIs F. (1978) Isolation of rat liver lysosomes by isopyenic centrifugation in a metrizamide gradient. J. cell. Biol. 78, 349-368. 